\title{
Project Lead The Way Students More Prepared For Higher Education
}

\author{
James P. Van Overschelde, Texas State University, USA
}

\begin{abstract}
Project Lead the Way (PLTW) is a hands-on, project-based engineering curriculum for high school and middle school students, which has quadrupled annual enrollment in Texas in five years to over 23,000 students. The diversity of students participating has also increased dramatically. Using six years of longitudinally-linked student data, the academic outcomes of cohorts of PLTW students were compared to matched cohorts of non-PLTW students. Matching was based on Grade 8 state math assessment scores and demographic and program participation variables. Findings show that PLTW students scored significantly higher on the state's Grade 11 mathematics assessment, a higher percentage met the college-ready criterion, a higher percentage enrolled in Texas higher education institutions, and the non-college-bound PLTW students earned higher wages.
\end{abstract}

Keywords: Engineering; Project-based Curriculum; Project Lead the Way; College Readiness

\section{INTRODUCTION}

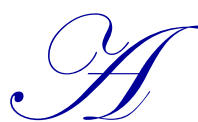

ccording to a recent U.S. Department of Commerce report (Langdon, McKittrick, Beede, Khan, \& Doms, 2011), "science, technology, engineering, and mathematics (STEM) workers drive our nation's innovation and competitiveness by generating new ideas, new companies, and new industries." In fact, growth in STEM-related jobs between 2008 and 2018 is expected to approach 20\%; a rate that is almost twice the growth rate of non-STEM related jobs and twice the growth rate seen during the first decade of this century. In addition to the rapid growth rate, current STEM-qualified workers are employed at a higher rate and earn an average of $26 \%$ more than non-STEM workers, but for workers with only a high school diploma the difference in earnings is almost 60\% (Langdon et al., 2011). The ability for the U.S. to meet this future growth is critical to the U.S. (and world) economy and the current inability of U.S. citizens to fill the growing number of STEM jobs is reflected in the passage of the bipartisan STEM Jobs Act of 2012 (H.R. 6429) in November 2012. In order for U.S. companies to have the skilled workforce they need to innovate and grow, this bill allocates 55,000 visas for highly-skilled immigrants holding advanced degrees in STEM fields from U.S. educational institutions.

Clearly, there is a need to educate a larger number of students who can fill these high paying STEM jobs than has been done previously. One national engineering program that has grown dramatically and been recognized for preparing more students for college STEM courses is Project Lead the Way (PLTW; NRC, 2007, p. 128-129). According to the developer, PLTW is a hands-on engineering curriculum for middle and high school students that engages students in "activities-, projects-, and problem-based learning" and is designed "to promote critical thinking, creativity, innovation, and real-world problem solving" while students apply the knowledge and skills learned in mathematics and science courses. Begun in New York in 1997, PLTW has experienced consistent growth with courses now offered in over 2,700 schools in all 50 states. Enrollment in PLTW is now estimated at 500,000 students, with 53,600 students added during the 2010-11 school year alone (Adam Giroux, personal communications, October 16, 2012). As you will see, Texas has experienced dramatic growth in PLTW enrollment over the last five years.

Although a fair number of studies have looked at the positive relationship between project-based learning in courses and mathematics achievement (Grier et al., 2008; Mergendoller, Maxwell, \& Bellisimo, 2006; for reviews, see Strobel \& van Barneveld, 2008; Thomas, 2000), very few studies have done the same for PLTW. In a 
study by Bottoms and Anthony (2005) of the Southern Regional Education Board (SREB), the academic outcomes of 274 high school students ${ }^{1}$ who took two or more PLTW courses were compared with a control group consisting of students who were selected based on a stratified random sample of 274 students (using gender, ethnicity, and parental education level) who took career/technical education (CTE) courses. Both groups of students participated in SREB's High Schools that Work (HSTW) program. The authors compared a snapshot of results for an assessment that was aligned with the National Assessment of Educational Proficiency (NAEP) and that had subtests for mathematics, science, and reading, and found that PLTW students scored significantly higher on all three subtests than the CTE control group ${ }^{2}$. However, Bottoms and Anthony did not control for potential differences in prior test performance and the students who selected to enroll in PLTW courses may have been higher performing students even before they took the PLTW courses. Consistent with the possibility that the PLTW students were initially higher performing, Bottoms and Anthony also observed that more of the PLTW students took four mathematics and four sciences courses than the CTE control group.

In a subsequent study by Bottoms and his colleague (Bottoms \& Ohn, 2007) in which PLTW students were defined as those who took three or more PLTW courses, they observed a similar pattern of results: 292 PLTW students scored significantly higher, on average, on the mathematics and science subtests (but not reading) than their CTE peers. In the next PLTW report (SREB, 2009), 641 self-reported PLTW students ${ }^{3}$ were compared to their CTE peers and even though the authors used a NAEP-aligned assessment that was different from the one used previously they found a similar pattern of results: a higher percentage of PLTW students met the SREB-defined criterion on each subtest. Unfortunately, these results are not definitive for two reasons. First, the three SREB studies all included PLTW and CTE students who were enrolled in special HSTW schools and therefore the results are less likely to generalize to traditional, comprehensive high school environments. Second, no performance data were used to determine if the control and PLTW groups were similar in the past before taking the CTE or PLTW courses, respectively.

In a more recent study, Tran and Nathan (2010) used a very small sample of 70 PLTW students, students who took one or more PLTW courses during the 2007-08 school year, and compared their academic performance on a state assessment in mathematics and science to 70 students in a matched control group. Students in the control group were hand matched with the PLTW students based on Grade 8 mathematics and science performance, gender, and economic disadvantage status ${ }^{4}$. Using a regression model, they found that PLTW students scored significantly lower in mathematics, but similarly in science, when compared to their non-PLTW peers. Although the methods of this study are somewhat more rigorous than the three SREB studies, the small sample size and the fact that students were included in the PLTW group even if they were currently taking their first PLTW course are problematic.

At first blush, the four prior studies described above can be interpreted as painting a conflicting image; three positive and one negative. But at closer examination, we can see that students who took two or more PLTW courses during high school consistently scored higher on a special NAEP-aligned mathematics, science, and reading assessment than matched CTE students. But, if PLTW students are defined as those who are currently taking a single PLTW course then we find a negative effect of PLTW on a state's mathematic assessment. The defining of what constitutes a PLTW student in the one negative study is problematic because PLTW defines two courses as foundational to their curriculum: Introduction to Engineering Design and Principles of Engineering.

The present study addresses the limitations of these prior studies in the following four ways. First, two substantially larger cohorts of students were used and they were longitudinally tracked for six years - over 4,100 students were in Grade 12 during the 2010-11 school year, and almost 2,900 students who graduated from high school during the 2009-10 school year. Students were included in the PLTW group only if they took two or more PLTW courses. Second, propensity score matching (PSM) was used to statistically match the PLTW students with non-PLTW students and a number of variables were included into the matching process that are known to be

\footnotetext{
${ }^{1}$ No grade-level information was provided in their study.

2 They compared mean test scores by $t$-test.

${ }^{3}$ PLTW students were defined as those who took three or more PLTW courses, as was done in Bottoms and Uhn (2007).

${ }^{4}$ They also used propensity score matching to examine the similarity of prior test scores between the two groups and found no significant differences.
} 
associated with academic success, including their scores on the state's Grade 8 mathematics assessment. Using PSM with these variables enables us to draw stronger causal conclusions from the results than were previously warranted. Third, although the prior studies found that PLTW students expressed a greater intention of going to college then their peers, I examined actual post-secondary enrollment. Fourth, for PLTW and non-PLTW students who did not enroll in college, their annual wages during the year following graduation were compared.

\section{METHODS}

In this quantitative research project, student-level data about students who participated in PLTW courses in secondary grades, as well as matched non-PLTW students, were obtained from the Texas Education Research Center (ERC) at the University of Texas at Austin. The authorization for Texas to create up to three ERCs was granted by the $79^{\text {th }}$ Texas Legislature in 2006. The ERCs are overseen by a 12-member Joint Advisory Board (JAB) of educational researchers that is chaired by the Texas Commissioners of Education and of Higher Education. Each ERC has a copy of one of the largest state-level educational data warehouse in the nation and it contains:

- Up to 20 years of annual data from the Texas Education Agency (oversees Pre-kindergarten [PK] to Grade 12 education) on Texas' 5 million students, 335,000+ teachers, 8,500+ campuses, and 1,237 districts, including: student enrollment, attendance, course taking, discipline, dropout, and assessment data, as well as teacher experience, role, and course data;

- Up to 20 years of annual data from the Texas Higher Education Coordinating Board's (oversees higher education) on 1.5 million students, including students enrollment, course taking, and graduation/certification;

- $\quad$ Five (5) years of State Board of Educator Certification data on P-12 teacher testing and certification;

- $\quad$ College Board assessment data for Advanced Placement and PSAT/SAT; and

- $\quad$ Twenty-one (21) years of employment, quarterly wage, and industry-of-employment data from the Texas Workforce Commission for people employed in Texas.

All data are de-identified and longitudinally linked from PK through college and into the workforce, enabling researchers, theoretically, to track a student from PK to retirement. Data are added/updated regularly by the appropriate state agency or organization and these data may be accessed only at ERC facilities after JAB approval.

Strict rules exist for how research project are approved by the JAB and how data are accessed, manipulated, summarized, and removed from the ERC (see statutes, procedures, \& policies listed in http://ritter.tea.state.tx.us/erc/JABpolicies.pdf). Texas State University is a collaborative partner with the University of Texas at Austin ERC. The ERC system is a nationally-lauded and US Department of Education Family Policy Compliance Office-approved educational data warehouse.

As required by Commissioner rule, the conclusions of this research do not necessarily reflect the opinions or official position of the Texas Education Agency, the Texas Higher Education Coordinating Board, or the State of Texas.

Research Questions. Using this vast ERC data warehouse, the research questions addressed by this study were:

1. How has enrollment in PLTW courses changed over the last five years and has the gender and ethnic makeup of students participating in PLTW diversified during that time?

2. Does participation in PLTW courses increase students' performance (i.e., met minimum standard, met college-readiness standard, scaled score) on state mathematic or English-language arts (ELA) assessments compared to matched non-PLTW students?

3. Does participation in PLTW courses increase college-going rates compared to matched non-PLTW students?

4. For students who do not attend college the year following high school graduation, do PLTW students earn more money compared matched non-PLTW students? 


\section{PLTW and non-PLTW Student Cohorts}

Two sets of student cohorts were created to answer Questions 2-4. The first included students who were in Grade 12 during the 2010-11 school year (hereafter, Grade 12 cohort) and the second included students who graduated from high school during the 2009-10 school year (hereafter, Graduate cohort). The following rules were used for selecting students for the cohorts.

Grade 12 Cohort. Students who were enrolled in Grade 12 during the 2010-11 school year made up the base dataset. This dataset included student-level information, including gender, ethnicity (coded Hispanic, White, other), economic disadvantaged status, limited English proficiency status (ELL, yes/no), gifted and talented participation status (GT, yes/no), and special education participation status (yes/no). To this dataset I added the same demographic and program participation data, plus grade level, but for the 2006-07 school year when the students traditionally would have been enrolled in Grade 8. Only students who were enrolled in Grade 8 in 2006-07 and Grade 12 in 2010-11 were retained for subsequent analyses.

To this dataset I added information about the number of PLTW courses each student took and completed successfully during the 2005-06, 2006-07, 2007-08, 2008-09, 2009-10, and 2010-11 school years. Students who completed two or more PLTW courses were selected for the PLTW group. Students who took one or no PLTW course were eligible for inclusion in the non-PLTW control group (see below for how students were selected for inclusion). We also added information about the Texas Assessment of Knowledge and Skills (TAKS) Mathematics and TAKS Reading/English-language arts (ELA) for the testing years 2007 (Grade 8) and 2010 (Grade 11). The information added included the scaled score, whether this scaled score met or exceeded the state's minimum standard for that assessment, and whether this scaled score met or exceeded the state's standard for college-readiness (technically referred to as Commended).

PSM was used to match non-PLTW students with PLTW students to create the matched control group. The Thoemmes (2012) instantiation of PSM for SPSS was used with a 1:1 matching strategy using gender, economic disadvantage status, ethnicity, ELL status, GT status, special education status, and scaled score on the state's Grade 8 Mathematics assessment - all from the 2006-07 school year. A total of 4,101 students were in the PLTW group and 4,099 were in the non-PLTW control group (see Table 1). To confirm that the PLTW and control groups were statistically similar, $t$-tests for each variable were conducted and no statistical differences were observed, all $t \mathrm{~s}<1$.

Table 1. Comparison of Grade 12 Students in the PLTW and Non-PLTW (Control) Cohorts after Propensity Score Matching, by Demographic and Program Participation Characteristics

\begin{tabular}{|c|c|c|}
\hline Comparison Variable & PLTW & Non-PLTW \\
\hline$N$ & 4,101 & 4,099 \\
\hline Math Scaled Score (mean) & 2328.8 & 2328.7 \\
\hline Female & $22.0 \%$ & $22.0 \%$ \\
\hline Gifted/Talented & $23.2 \%$ & $23.2 \%$ \\
\hline Special Education & $2.8 \%$ & $2.8 \%$ \\
\hline ELL & $2.9 \%$ & $2.8 \%$ \\
\hline \multicolumn{3}{|l|}{ Ethnicity } \\
\hline Hispanic & 1,681 & 1,683 \\
\hline Other & 802 & 800 \\
\hline White & 1,618 & 1,616 \\
\hline \multicolumn{3}{|c|}{ Economic Disadvantage Status } \\
\hline None & 2,493 & 2,492 \\
\hline Free Lunch & 1,022 & 1,022 \\
\hline Reduced Price Lunch & 376 & 375 \\
\hline Other Public Assistance & 210 & 210 \\
\hline
\end{tabular}

Note: The ethnicity of African American, Asian, and Native American students was aggregated into a single Other category to protect the confidentiality of students as required by the Family Educational Rights and Privacy Act (FERPA). 
Graduate Cohort. This cohort was created in an almost identical manner, except the students had to have been in the graduating Class of 2010 (graduated during the 2009-10 school year), been enrolled in Grade 12 during the 2009-10 school year, and been enrolled in Grade 8 during the 2005-06 school year. These graduates were selected so that post-secondary information for the 2010-11 school year could be added for those students who enrolled in college during the year following high school graduation. For these students, TAKS data for 2006 (Grade 8) and 2009 (Grade 11) were used. Data about post-secondary enrollment in Texas institutions of higher education (IHE) for Fall 2010 and Spring 2011 semesters was added from the four types of IHEs that exist in Texas: community college, university, health-related, and private. Finally, using unemployment insurance wage data from the Texas Workforce Commission, I added the third quarter of 2010 wages for all students contained in the final dataset.

A total of 2,876 students were in the PLTW group and 2,876 were in the control group (see Table 2). To confirm that the PLTW and control groups were statistically similar, $t$-tests for each variable were conducted and no statistical differences were observed, all $t$ s $<1$.

Table 2. Comparison of Class of 2010 Graduates Who were in the PLTW and Non-PLTW (Control) Cohorts after Propensity Score Matching, by Demographic and Program Participation Characteristics

\begin{tabular}{|c|c|c|}
\hline Comparison Variable & PLTW & Non-PLTW \\
\hline $\mathbf{N}$ & 2,876 & 2,876 \\
\hline Math Scaled Score (mean) & 2326.4 & 2326.4 \\
\hline Female & $19.1 \%$ & $19.1 \%$ \\
\hline Gifted/Talented & $25.1 \%$ & $25.0 \%$ \\
\hline Special Education & $3.9 \%$ & $3.9 \%$ \\
\hline ELL & $1.8 \%$ & $1.7 \%$ \\
\hline \multicolumn{3}{|l|}{ Ethnicity $^{5}$} \\
\hline Asian & 152 & 150 \\
\hline African American & 356 & 358 \\
\hline Hispanic & 1,681 & 1,683 \\
\hline Native American & 14 & 15 \\
\hline White & 1,618 & 1,616 \\
\hline \multicolumn{3}{|c|}{ Economic Disadvantage Status } \\
\hline None & 1,916 & 1,914 \\
\hline Free Lunch & 618 & 618 \\
\hline Reduced Price Lunch & 229 & 230 \\
\hline Other Public Assistance & 113 & 114 \\
\hline
\end{tabular}

\section{RESULTS}

To answer the first question about overall PLTW enrollment, I analyzed course completion data for all PLTW courses during the last five years. Total PLTW enrollment in Texas increased dramatically from 4,498 students in 2006-07 to 23,184 in 2010-11 - a 415\% growth rate. In central Texas where much effort by school districts has focused on expanding PLTW, the PLTW enrollment now accounts for $3.0 \%$ of the high school student population, whereas PLTW accounts for $1.1 \%$ of the high school population in the rest of the state (see Figure 1).

In addition to the dramatic increase in overall student participation in PLTW, the diversity of the enrollment has changed. Using chi-square test, there was a greater than expected increase in female participation with young woman participation increasing by $586 \%$ (623\% in central Texas), whereas the male population increased by a large, but substantially smaller, 385\%. A similar significant pattern was observed for Hispanic students with a $507 \%$ growth rate over five years (467\% in central Texas) compared to White student enrollment. Finally, there was a significant $650 \%$ increase in the number of economically disadvantaged students who participated in PLTW.

\footnotetext{
${ }^{5}$ The ethnicity of African American, Asian, and Native American students was aggregated into a single Other category to protect the confidentiality of students as required by the Family Educational Rights and Privacy Act (FERPA).
} 


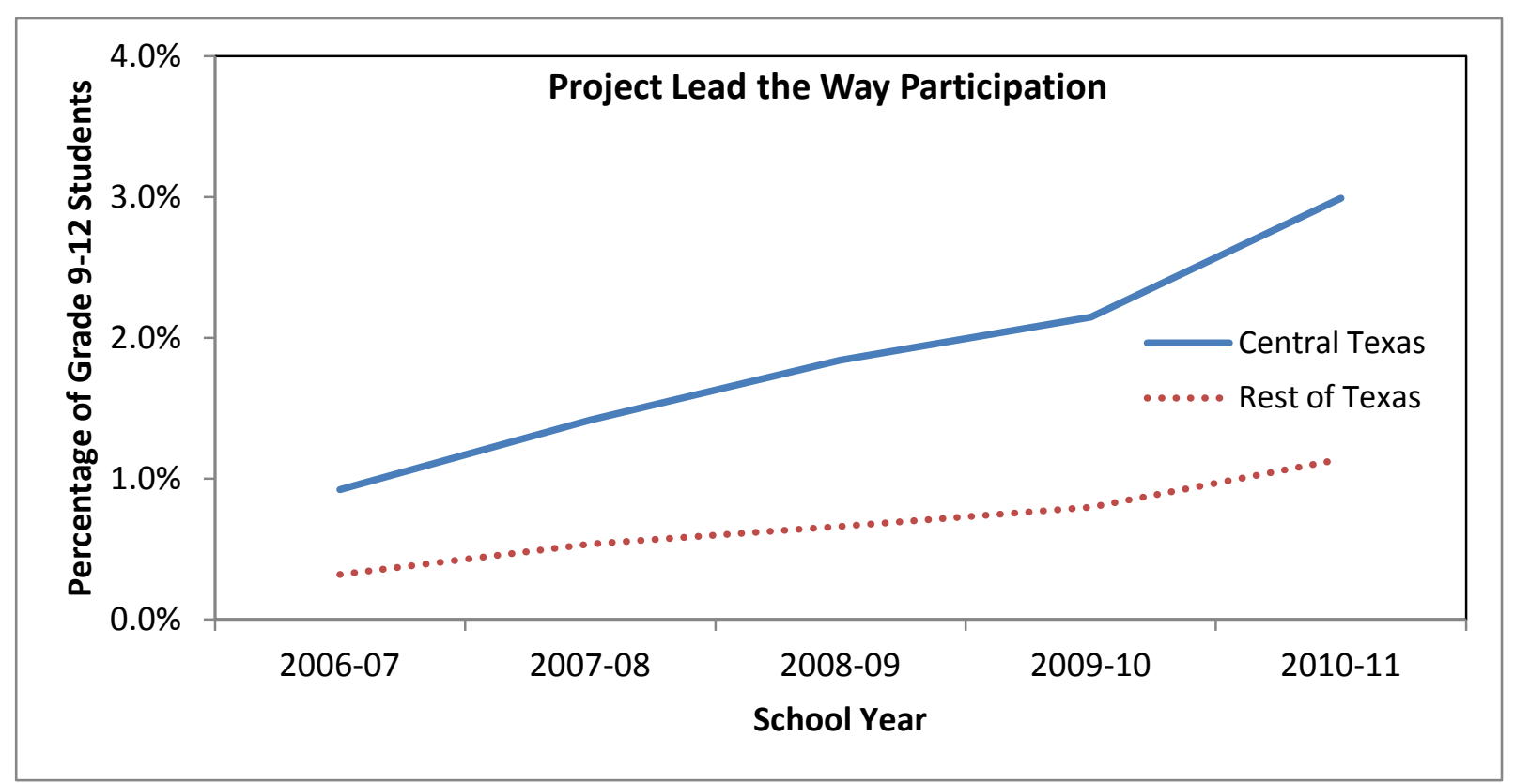

Figure 1. Percentage of Students in Grades 9-12 Who Participate in Project Lead the Way in Central Texas and in the Rest of the State

\section{Grade 12 Cohort Analysis}

To determine whether the Grade 12 cohorts performed at different levels on the TAKS Grade 11 Mathematics assessment, three different analysis of variances (ANOVA) were computed with the dependent variables (DV) of met standard (Met, $0=$ No, $1=$ Yes), met college-ready standard $(\mathrm{CR}, 0=\mathrm{No}, 1=\mathrm{Yes}$ ), and scaled score (SS) ${ }^{6}$. The independent variables (IV) were: group (PLTW, non-PLTW), gender, ethnicity (Hispanic, White, other), economic disadvantage status, and program participation statuses for 2006-07 including GT, ELL, and special education. The only interactions included were between group and ethnicity, gender, and economic disadvantage status. A summary of the results are presented in Table 3.

Mathematics Met Standard. The cohort group was significant, $F(1,8187)=4.89, p<.027$, with a higher percentage of PLTW students meeting the minimum state standard $(M=91.2 \%)$ than the matched control group $(M=90.2 \%)$. Of the interactions, only the interaction with ethnicity approached significant, $F(2,8187)=2.53, p=.08$. A higher percentage of Hispanic students who participated in PLTW met the minimum standard $(M=92.1 \%)$ than their nonPLTW peers $(M=90.2 \%)$, and there were no significant differences between White student $\left(M_{\text {PLTW }}=92 \%, M_{\text {Control }}\right.$ $=91 \%)$ nor between Other students $\left(M_{\mathrm{PLTW}}=89.4 \%, M_{\text {Control }}=89.5 \%\right)$.

Mathematics College-Ready Standard. The cohort group was significant, $F(1,8187)=8.58, p=.003$, with a higher percentage of PLTW students meeting the college-ready standard $(M=41.1 \%)$ than the matched control group $(M=$ $37.3 \%)$. None of the interactions with cohort group approached significance, all $F \mathrm{~s}<1$.

Mathematics Scaled Score. Of greatest importance, the cohort group was significant, $F(1,8187)=14.76, p=.0001$. The PLTW group had a significantly higher mean scaled score $(M=2337.6)$ than the matched control group $(M=$ 2321.7). None of the interactions with group approached significance, all $F \mathrm{~s}<1.47$.

\footnotetext{
${ }^{6}$ Ideally, logistic regression would have been used for the dichotomous Met Standard and Met College-Ready Standard, but the ERC did not have this SPSS module installed. 
Table 3. Descriptive Statistics for the Grade 11 TAKS Mathematics Assessment for the Grade 12 and Graduate Cohorts, and the Post-Secondary Enrollment for the Graduate Cohort.

\begin{tabular}{|c|c|c|c|c|}
\hline & \multicolumn{2}{|c|}{ Grade 12 Cohort } & \multicolumn{2}{|c|}{ Graduate Cohort } \\
\hline & PLTW & Non-PLTW & PLTW & Non-PLTW \\
\hline Grade 11 Math Met Standard \% & $91.2 \%$ & $90.2 \%$ & $85.6 \%$ & $83.6 \%$ \\
\hline Grade 11 Math College-Ready \% & $41.1 \%$ & $37.3 \%$ & $45.0 \%$ & $40.0 \%$ \\
\hline Grade 11 Math Scaled Score (mean) & 2337.6 & 2321.7 & 2343.6 & 2320.7 \\
\hline Post-Secondary Enrollment \% & N/A & N/A & $62.1 \%$ & $58.4 \%$ \\
\hline
\end{tabular}

Notes: Post-secondary enrollment included 2-year and 4-year, public and private institutions in Texas.

ELA Met Standard. The main effect of cohort group was not significant, $F<1$, and none of the interactions were significant, all $F \mathrm{~s}<1.92$.

ELA College-Ready Standard. The main effect of cohort group was not significant, $F<1$, and none of the interactions were significant, all $F \mathrm{~s}<2.42$.

ELA Scaled Score. The main effect of cohort group was not significant, $F<1$, but there was a marginally significant interaction with economic disadvantage status, $F(1,8130)=3.53, p=.06$. For the non-PLTW group, low income students scored significantly lower $(M=2269.7)$ than their non-low income peers $(M=2324.1)$, whereas for the PLTW group, the low income students scored $(M=2275.6)$ more similarly, but still significantly lower than their non-low income peers $(M=2317.5)$. The other interactions were not significant, $F \mathrm{~s}<1$.

\section{Graduate Cohort Analysis}

To determine whether the Graduate cohorts performed at different levels on the TAKS Grade 11 Mathematics assessment, three ANOVAs were computed with the same three DVs used with the Grade 12 cohort. The IVs were the same except the program participation data were for 2005-06. A similar set of analyses was performed on the TAKS Grade 11 ELA assessment. Finally, an ANOVA was performed with the DV of whether the student enrolled in an IHE during the school year following high school graduation.

Mathematics Met Standard. The cohort group was significant, $F(1,5739)=7.15, p=.008$, with a higher percentage of PLTW students meeting the minimum state standard $(M=85.6 \%)$ than the matched control group $(M=83.6 \%)$. Of the interactions, only the interaction with economic disadvantaged status approached significance, $F(1,5739)=$ $3.52, p=.061$ (see Figure 2). A higher percentage of low-income students who participated in PLTW met the minimum standard $(M=84.9 \%)$ than their non-PLTW peers $(M=81.8 \%)$, and there was no significant difference between for the non-low-income students $\left(M_{\mathrm{PLTW}}=86.2 \%, M_{\mathrm{Control}}=85.5 \%\right)$.

Mathematics College-Ready Standard. The cohort group was significant, $F(1,5739)=9.09, p=.003$, with a higher percentage of PLTW students meeting the college-ready standard $(M=45.0 \%)$ than the matched control group $(M=$ $40.0 \%$ ). None of the interactions with cohort group approached significance, all $F \mathrm{~s}<1.44$.

Mathematics Scaled Score. Of greatest importance, the cohort group was significant, $F(1,5739)=14.91, p=.0001$. The PLTW group had a significantly higher mean scaled score $(M=2343.6)$ than the matched control group $(M=$ 2320.7). None of the interactions with group approached significance, all $F_{\mathrm{s}}<1.71$.

ELA Met Standard. There was a main effect of cohort group, $F(1,5709)=4.69, p=.03$, with a higher percentage of PLTW students $(M=90.2 \%)$ meeting the state's minimum standard in ELA than the non-PLTW students $(M=$ $89.2 \%)$. As was observed with Mathematics, there was a significant interaction of cohort group with economic disadvantage status, $F(1,5709)=5.11, p=.024$. For low-income students, a higher percentage of PLTW students $(M=90.4 \%)$ met the standard than non-PLTW students $(M=88.4 \%)$, and for the non-low income students there was no difference in the percentages between PLTW $(M=90.1 \%)$ and non-PLTW $(M=90.1 \%)$ students. 


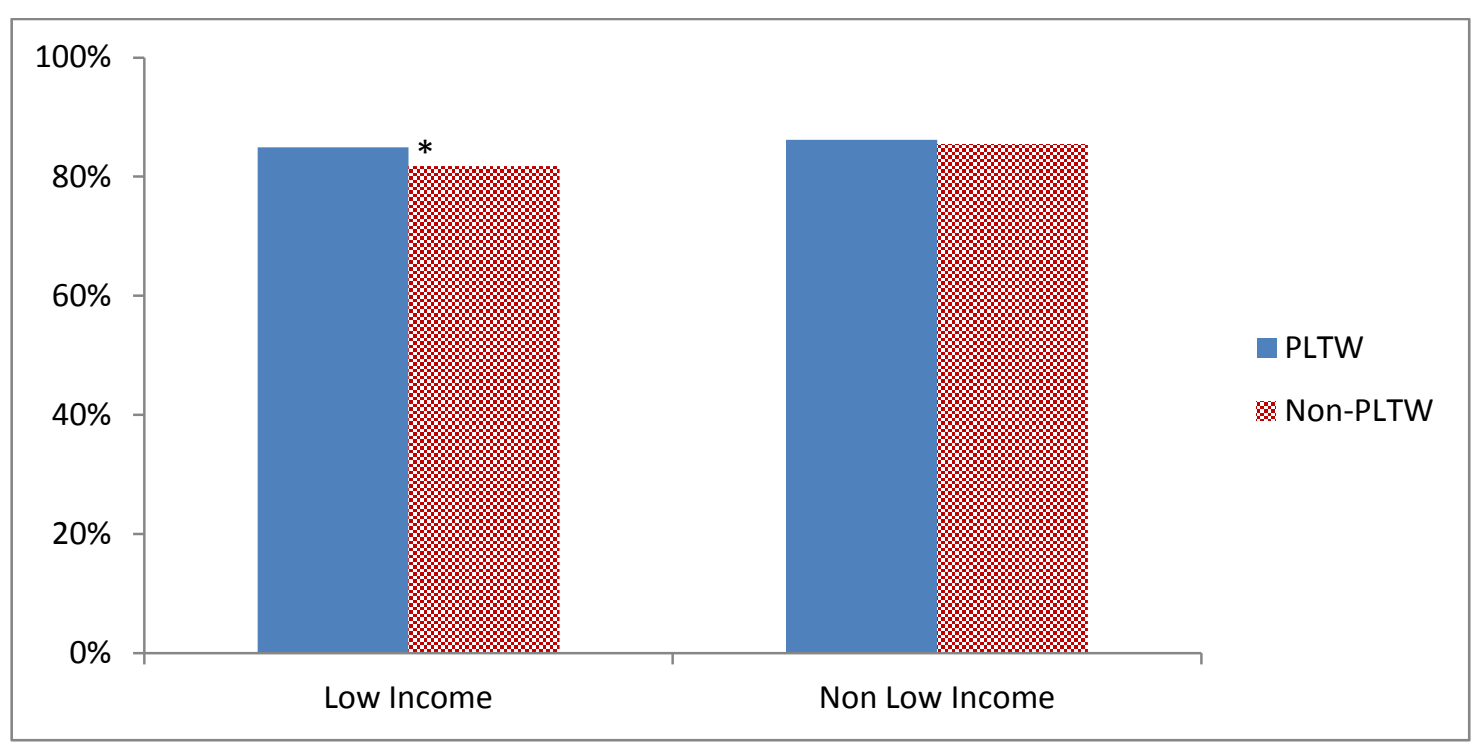

Figure 2. Percentage of Students Meeting the State's Grade 11 Mathematics Minimum Standard, by Economic Disadvantage Status Note: * indicates significant difference.

ELA College-Ready Standard. There was no main effect of cohort group, $F<1$, but again there was a significant interaction economic disadvantage status, $F(1,5709)=8.12, p=.004$. For the low-income students, PLTW students were more college ready $(M=30.5 \%)$ than non-PLTW students $(M=25.6 \%)$, whereas for the more affluent students, PLTW and non-PLTW students were equally college ready $(M=37.2 \%$ and $41.0 \%$, respectively). There was also a significant interaction of cohort group with ethnicity, $F(2,5709)=3.78, p=.023$. Post-hoc analyses revealed that for the PLTW students, the White students $(M=40.8 \%)$ were more college ready than the Hispanic $(M$ $=30.9 \%)$ or Other $(M=29.8 \%)$ students, but for the non-PLTW students, there were no significant differences, although White students $(M=35.2 \%)$ scored nominally higher than the other two groups $(M=33.6 \% \& 31.2 \%$, respectively).

ELA Scaled Score. Similar to the finding with the Grade 12 cohort, the main effect of cohort group was not significant, $F<1$, but there was a significant interaction with economic disadvantage status, $F(1,5709)=4.65, p=$ .031. For the non-PLTW group, low income students scored significantly lower $(M=2266.4)$ than the non-low income students $(M=2310.4)$, and for the PLTW group the low-income students scored $(M=2276.9)$ more similarly, but still significantly lower than the non-low income students $(M=2303.2)$. The other interactions were not significant, $F$ s $<2.40$.

Post-Secondary Enrollment. The main effect of cohort group was significant, $F(1,5739)=5.61, p=.018$, with PLTW students enrolling in a Texas IHE at a higher rate $(M=62.1 \%)$ than their non-PLTW peers $(M=58.4 \%)$. There was a significant interaction of cohort group with gender $(F(1,5739)=4.77, p=.03$; see Figure 3 ). Postsecondary enrollment was greater for females than males in the non-PLTW group $\left(M_{\text {male }}=53.7 \%, M_{\text {female }}=63.1 \%\right)$, whereas the difference was not significant for the PLTW group $\left(M_{\text {male }}=60.7 \%, M_{\text {female }}=63.5 \%\right)$.

In addition, there was a significant interaction of cohort group with economic disadvantage status $(F(1$, $5739)=4.66, p=.03$; see Figure 4). Post-secondary enrollment was greater for non-low-income students than their low-income peers in the non-PLTW group $\left(M_{\text {non-econ }}=62.9 \%, M_{\text {econ }}=53.8 \%\right)$, but the difference was not significant for the PLTW group $\left(M_{\text {non-econ }}=63.6 \%, M_{\text {econ }}=60.7 \%\right)$. 


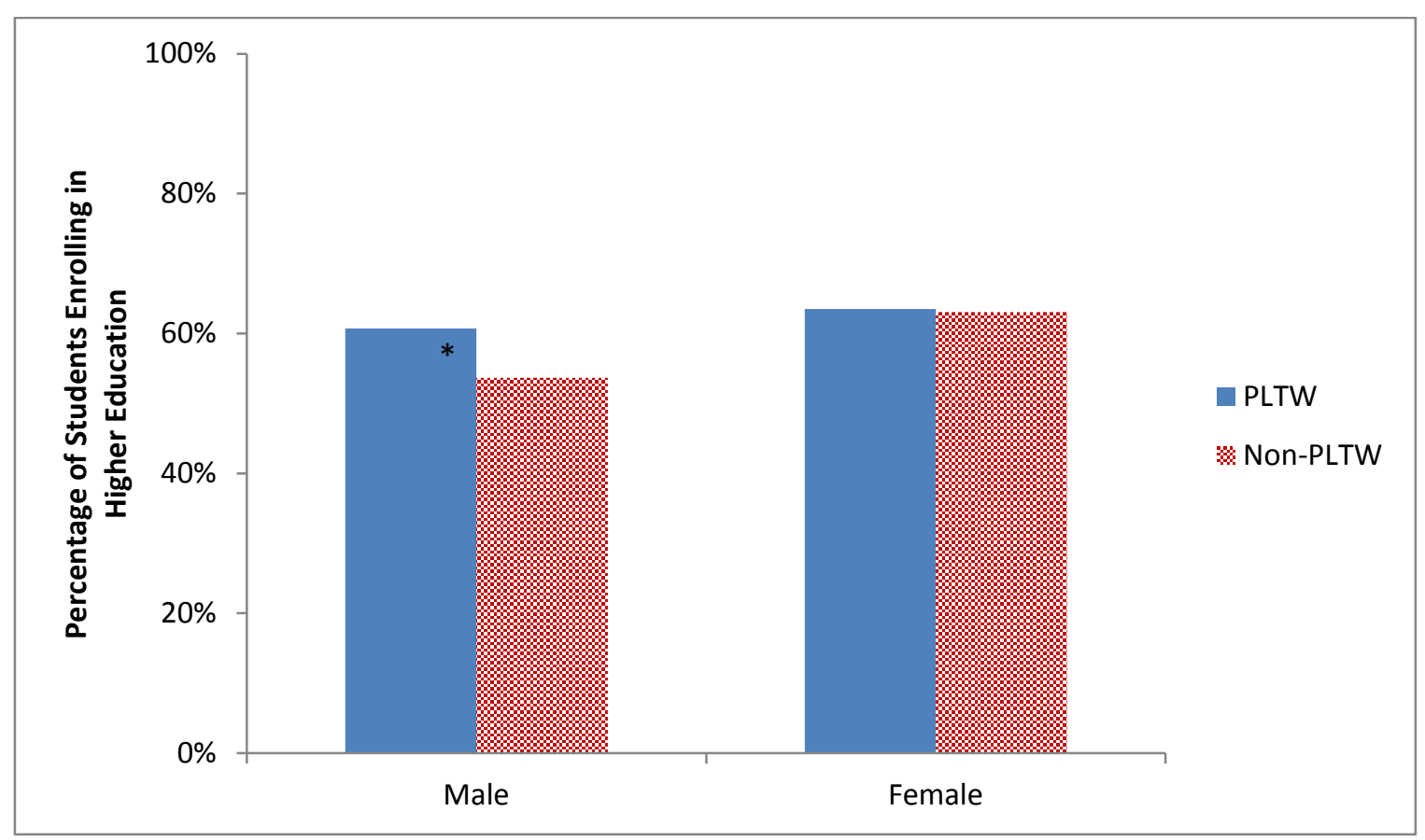

Figure 3. Percentage of Students Enrolling in an Institution of Higher Education During the School Year Following Graduation from High School, by Gender Note: * indicates significant difference.

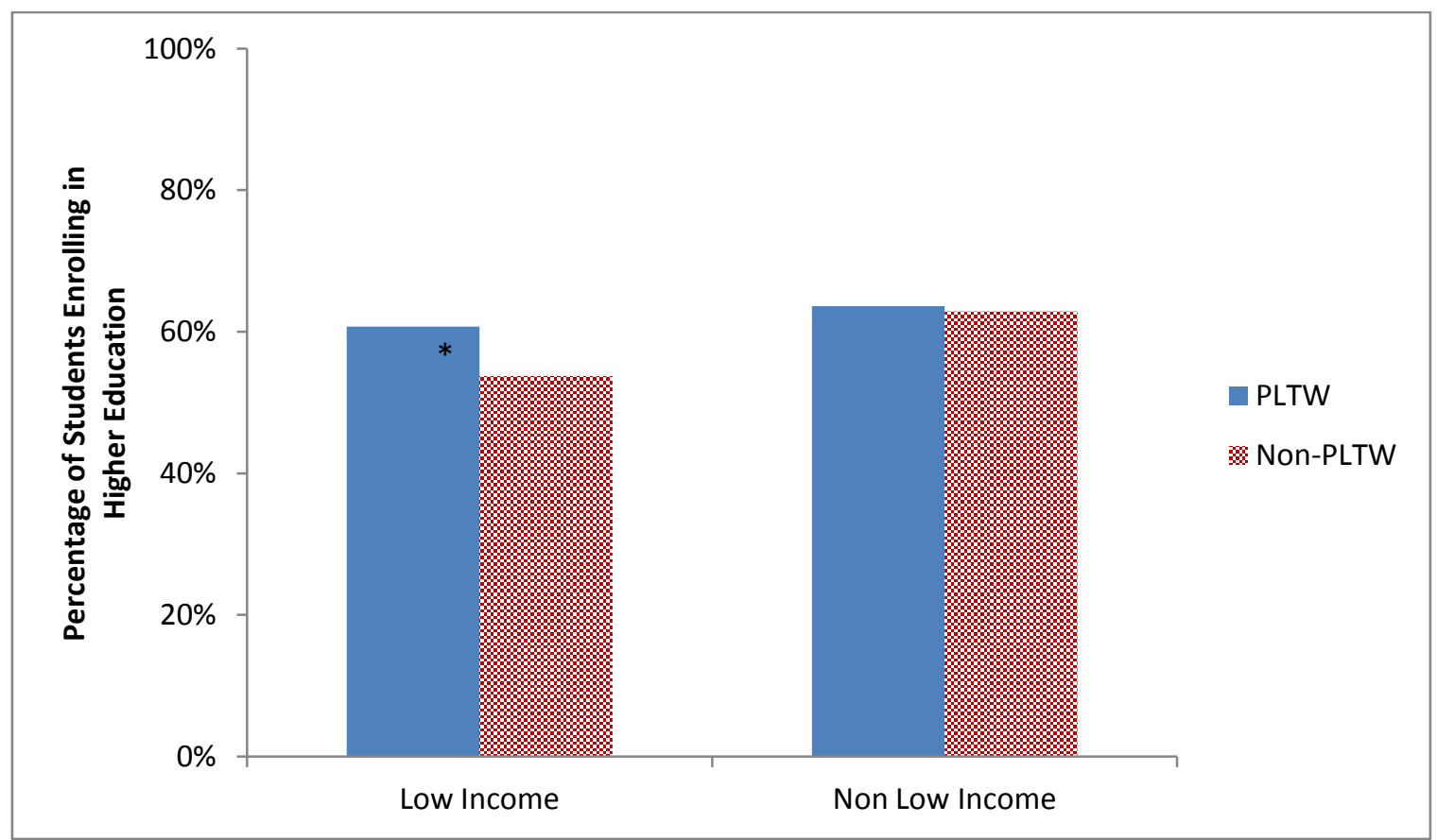

Figure 4. Percentage of Students Enrolling in an Institution of Higher Education During the School Year Following Graduation from High School, by Economic Disadvantage Status Note: * indicates significant difference.

Salary. Finally, for the students in both groups who did not enroll in a Texas IHE but who were employed in Texas, I computed the median salary for the four quarters following high school graduation. The PLTW students had a higher median salary $(\$ 27,986)$ than their matched peers $(\$ 24,628)$. Thus, despite the fact that a greater percentage 
of PLTW students enrolled in a post-secondary institution following high school graduations, the students who did not enroll still earned $13.6 \%$ more than the matched, non-PLTW students.

\section{CONCLUSIONS}

The results from this study are clear. During the last half decade, overall PLTW enrollment in Texas has increased by over $400 \%$, and enrollment by traditionally underrepresented student groups (Hill, Corbett, \& St. Rose, 2010) has risen at even faster rates. PLTW enrollment of Hispanic students has grown by over $500 \%$, of women by almost $600 \%$, and of low-income students by $650 \%$.

In spite of the fact that traditionally lower-performing students were enrolled in PLTW courses in higher numbers, students who participated in PLTW were more prepared for higher education. Specifically and in comparison to matched, non-PLTW students, PLTW students scored higher on the state's mathematics assessment, a higher percentage met the state's minimum Mathematics standard, and a higher percentage met the college-ready Mathematics standard. This pattern obtained for students who were in Grade 12 in 2010-11 and for students who were in Grade 12 and also graduated during the 2009-10 school year. In addition, PLTW students attended Texas higher education institutions at a higher rate than matched, non-PLTW students. For those students who did not enroll in an IHE, the median wage for PLTW students was 13.6\% higher than for the non-PLTW students.

The pattern of results for the state's ELA assessment was less consistent. For most but not all of the analyses, there was a significant interaction of cohort group with economic disadvantage status with the differences in performance between low-income PLTW students and non-low-income PLTW students being smaller than (or non-existent) the differences between low-income non-PLTW students and non-low-income non-PLTW students. And, only for the Grade 12 cohort there was no main effect or interaction of cohort group for the percentage of students who met the state's minimum standard or the state's college-ready standard.

In future research, the PLTW students and their matched, non-PLTW peers will be tracked longitudinally for the next few years to determine how well both groups persisted in higher education, and to determine what majors the students pursued. I am curious to see if PLTW students are more likely to enroll and persist in STEM disciplines relative to non-PLTW students.

In addition, a large number of school districts in Texas are implementing PLTW in middle school and I will be able to track cohorts of middle school students through high school to determine if similar positive patterns are obtained.

\section{AUTHOR INFORMATION}

Dr. James P. Van Overschelde is Assistant Professor and co-Director of the Office of Educator Preparation in the College of Education at Texas State University - San Marcos where he teaches graduate level courses in research methods as well as manages the ongoing, formative evaluation of the University's educator preparation program. His research interests are in STEM education, educator preparation, and the application of cognitive psychological research findings to improving education. E-mail: jv23@txstate.edu

\section{REFERENCES}

1. Barron, B., \& Darling-Hammond, L. (2008). Teaching for meaningful learning: A review of research on inquiry-based and cooperative learning. San Francisco, CA: Jossey-Bass. Excerpt retrieved from http://www.edutopia.org/pdfs/edutopia-teaching-for-meaningful-learning.pdf

2. Bottoms, G., \& Anthony, K. (2005). Project Lead the Way: A pre-engineering curriculum that works. Atlanta, GA: Southern Regional Education Board. Retrieved from http://publications.sreb.org/2005/05V08_Research_PLTW.pdf

3. Bottoms, G., \& Uhn, J. (2007). Project Lead the Way works: A new type of career and technical program. Atlanta, GA: Southern Regional Education Board. Retrieved from http://publications.sreb.org/2007/07V29_Research_Brief_PLTW.pdf 
4. Hill, C., Corbett, C., \& St. Rose, A. (2010). Why so few? Women in science, technology, engineering, and mathematics. Washington, DC: American Association of University Women. Retrieved from http://www.aauw.org/learn/research/upload/whysofew.pdf

5. Geier, R., Blumenfeld, P.C., Marx, R.W., Krajcik, J.S., Fishman, B., Soloway, E., \& Clay-Chambers, J. (2008). Standardized test outcomes for students engaged in inquiry-based science curricula in the context of urban reform. Journal of Research in Science Teaching, 45(8), 922-939.

6. Langdon, D., McKittrick, G., Beede, D., Khan, B., \& Doms, M. (2011). STEM: Good jobs now and for the future (ESA Issue Brief \#03-11). Washington, DC: U.S. Department of Commerce, Economics and Statistics Administration.

7. Mergendoller, J. R., Maxwell, N. L., \& Bellisimo, Y. (2006). The effectiveness of problem-based instruction: A comparative study of instructional methods and student characteristics. The Interdisciplinary Journal of Problem-Based Learning, 1(2). http://dx.doi.org/10.7771/1541-5015.1026

8. National Research Council. (2007). Rising above the gathering storm: Energizing and employing America for a brighter economic future. Washington, DC: The National Academies Press. Retrieved from http://www.nap.edu/catalog.php?record id=11463

9. Rosenberg, N. (2004). Innovation and economic growth. OECD. Retrieved from http://www.oecd.org/cfe/tourism/34267902.pdf

10. Southern Regional Education Board. (2009). The next step for career/technical programs: Project Lead the Way and the merging of academic and career/technical studies. Atlanta, GA: Author. Retrieved from http://publications.sreb.org/2009/09V15 PLTW_Research_Brief.pdf

11. Strobel, J., \& van Barneveld, A. (2008). When is PBL more effective? A meta-synthesis of meta-analyses comparing PBL to conventional classrooms. Interdisciplinary Journal of Problem-Based Learning, 3(1), 44-58. Retrieved from http://docs.lib.purdue.edu/ijpbl/vol3/iss1/4)

12. Thoemmes, F. (2012). Propensity score matching in SPSS. Retrieved March 2012 at http://arxiv.org/ftp/arxiv/papers/1201/1201.6385.pdf

13. Thomas, J. W. (2000). A review of research on project-based learning. Retrieved from http://www.bie.org/images/uploads/general/9d06758fd346969cb63653d00dca55c0.pdf

14. Tran, N. A., \& Nathan, M. J. (2010). Pre-college engineering studies: An investigation of the relationship between pre-college engineering studies and student achievement in science and mathematics. Journal of Engineering Education, 143-157. Retrieved from http://www.jee.org/2010/april/6.pdf 


\section{NOTES}

